\author{
Lukasz POLUS ${ }^{1}$ \\ Maciej SZUMIGAŁA ${ }^{2}$
}

\title{
WPLYW TARCIA NA NOŚNOŚĆ BELKI ALUMINIOWO-BETONOWEJ
}

\begin{abstract}
W artykule przedstawiono wpływ tarcia, występującego między aluminiową belką a stalowa blachą fałdowa pełniąca funkcję deskowania płyty żelbetowej, na nośność belki zespolonej aluminiowo - betonowej. Belki aluminiowo - betonowe są stosunkowo nowym rodzajem konstrukcji w porównaniu do belek stalowobetonowych. Konstrukcje aluminiowe mają wiele zalet. Możliwy jest ich pełen recykling, a materiał jest odporny na korozję. Konstrukcje zespolone aluminiowo - betonowe w związku z większą odpornością aluminium na korozję wydają się być trwalsze od konstrukcji stalowo - betonowych. Możliwa jest jednak korozja na powierzchni styku aluminium ze stalą w belkach z płytą żelbetową wylaną na stalowej blasze fałdowej. $\mathrm{Z}$ tego powodu należy odizolować belkę aluminiową od blachy stalowej stosując przekładki. Zastosowanie przekładki np. elastomerowej redukuje wpływ tarcia na powierzchni styku aluminium - stal. W artykule oceniono wpływ wielkości współczynnika tarcia oraz jego zupełnego pominięcia na nośność belki zespolonej aluminiowo - betonowej. Przygotowano model składający się z aluminiowej dwuteowej belki i płyty żelbetowej wykonanej na stalowej blasze fałdowej. Z obliczeń numerycznych otrzymano, że wpływ tarcia na nośność na zginanie jest pomijalnie mały. Stąd zasadne jest stosowanie przekładek zapobiegających korozji na styku aluminium - stal, nawet jeśli mają one zmniejszyć tarcie występujące między w/w materiałami. Planowane są badania laboratoryjne belki zespolonej aluminiowo-betonowej przedstawionej w artykule oraz badania podatności łączników.
\end{abstract}

Słowa kluczowe: konstrukcje zespolone aluminiowo-betonowe, analiza numeryczna nośności

\section{Wprowadzenie}

Coraz częściej jako materiał konstrukcyjny wykorzystuje się stopy aluminium. Każda nowa budowla związana jest $\mathrm{z}$ trwałymi i nieodwracalnymi zmianami w środowisku [1].

1 Autor do korespondencji: Łukasz Polus, Instytut Konstrukcji Budowlanych, Piotrowo 5, 60-965 Poznań, 61665 2098, lukasz.polus@ @ut.poznan.pl.

${ }^{2}$ Maciej Szumigała, Instytut Konstrukcji Budowlanych, Piotrowo 5, 60-965 Poznań, 61665 2401, maciej.szumigala@put.poznan.pl. 
Projektanci powinni szukać trwałych rozwiązań, które będą ograniczały zużycie zasobów naturalnych [2]. Różnica pomiędzy ceną stopów aluminiowych a stalą jest znaczna, ale wraz z rozwojem technologii produkcji ulega zmniejszeniu. Konstrukcje aluminiowe mają wiele zalet. Możliwy jest ich pełen recykling [3], a materiał jest odporny na korozję dzięki występującej na powierzchni aluminium warstewce tlenku glinu [6]. Z najczęściej stosowanych materiałów konstrukcyjnych stopy aluminium są najlżejsze. Najcięższym materiałem (w proporcji: ciężar do wytrzymałości) jest beton, potem stal i drewno [3]. Konstrukcje zespolone aluminiowo-betonowe w związku z większą odpornością aluminium na korozję wydają się być trwalsze od konstrukcji stalowobetonowych, których zasady wymiarowania zostały przedstawione w [5], [7]. Konstrukcje aluminiowe projektuje się wg [8]. W związku z brakiem normy dla konstrukcji aluminiowo-betonowych, przy określaniu parametrów belki zespolonej aluminiowo-betonowej skorzystano z wytycznych podanych w [7].

\section{Analiza numeryczna wpływu tarcia na nośność belki}

Dane dotyczące analizowanej belki zespolonej aluminiowo-betonowej zebrano w tabeli 1. Belkę przedstawiono na rys. 1 . Specjalne łączniki, które wykorzystano do połączenia belki aluminiowej z płytą betonową zostały opisane $\mathrm{w}[10] \mathrm{i}[11]$.

Tabela 1. Belka zespolona aluminiowo-betonowej

Table 1. Composite aluminium and concrete beam

\begin{tabular}{|c|c|c|c|}
\hline Parametr & Symbol & Wartość & Jednostka \\
\hline Rozpiętość belki & $\mathrm{L}$ & 5,20 & $\mathrm{~m}$ \\
\hline Schemat belki & \multicolumn{3}{|c|}{ swobodnie podparta } \\
\hline Wysokość płyty betonowej & $\mathrm{h}$ & 150,0 & $\mathrm{~mm}$ \\
\hline Szerokość płyty betonowej & $\mathrm{b}$ & 656,0 & $\mathrm{~mm}$ \\
\hline Grubość betonu nad blachą trapezową & $\mathrm{h}_{\mathrm{c}}$ & 95,0 & $\mathrm{~mm}$ \\
\hline Stop aluminium & \multicolumn{3}{|c|}{ EN AW-6063 T6 } \\
\hline Granica plastyczności stopu aluminium & $f_{o}$ & 170 & $\mathrm{MPa}$ \\
\hline Wytrzymałość na rozciąganie stopu aluminium & $\mathrm{f}_{\mathrm{u}}$ & 215 & $\mathrm{MPa}$ \\
\hline Przekrój aluminiowy & \multicolumn{3}{|c|}{ Dwuteownik, klasa przekroju: 3} \\
\hline Wysokość przekroju aluminiowego & $\mathrm{h}_{\mathrm{a}}$ & 300 & $\mathrm{~mm}$ \\
\hline Szerokość półki przekroju aluminiowego & $b_{f}$ & 170 & $\mathrm{~mm}$ \\
\hline Grubość półki przekroju aluminiowego & $t_{f}$ & 15 & $\mathrm{~mm}$ \\
\hline Grubość środnika przekroju aluminiowego & $t_{w}$ & 8 & $\mathrm{~mm}$ \\
\hline Beton & \multicolumn{3}{|c|}{$\mathrm{C} 35 / 45$} \\
\hline Średnica sworznia & $\mathrm{d}$ & 19 & $\mathrm{~mm}$ \\
\hline Materiał sworznia & \multicolumn{3}{|c|}{$\mathrm{S} 235$} \\
\hline Rozstaw łączników & \multicolumn{3}{|c|}{$233,0 \mathrm{~mm}$} \\
\hline Blacha trapezowa & \multicolumn{3}{|c|}{ T55P grubość 1mm, stal S235 } \\
\hline
\end{tabular}




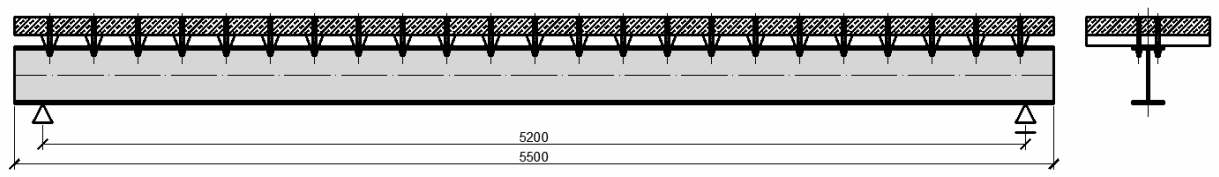

Rys. 1. Belka aluminiowo-betonowa

Fig. 1. Aluminium and concrete beam

Analizę numeryczną przeprowadzono w programie Abaqus. Model belki zespolonej przedstawiono na rys. 2 .

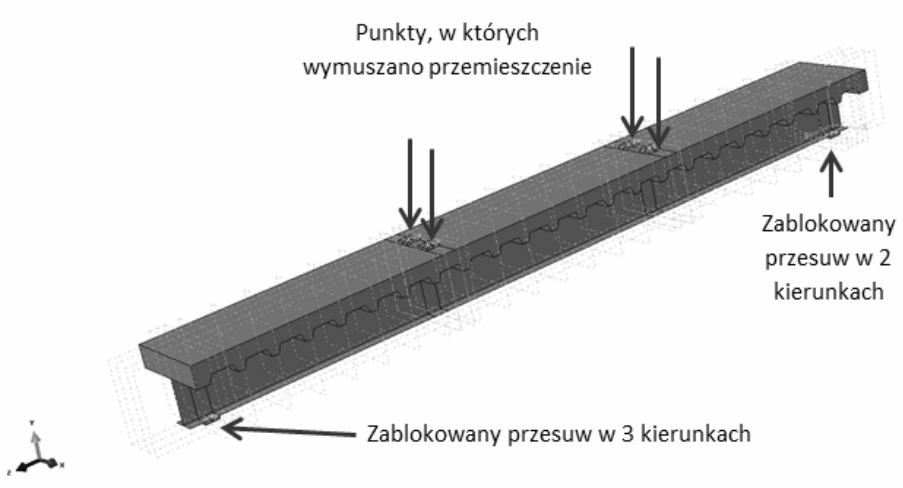

Rys. 2. Model belki aluminiowo-betonowej

Fig. 2. Model of aluminium and concrete beam

Model składa się z aluminiowej dwuteowej belki i płyty żelbetowej wykonanej na stalowej blasze fałdowej. Łączniki sworzniowe „,zatopiono” w betonie. W modelu numerycznym geometrię modelu zastąpiono elementami skończonymi: płyta betonowa - ośmiowęzłowe prostopadłościenne elementy skończone typu solid, aluminiowa belka - elementy czterowęzłowe typu shell, blacha fałdowa jako „skin” - elementy czterowęzłowe typu shell, łączniki - elementy prętowe typu beam. Prawa fizyczne dla przyjętych w analizie materiałów przedstawiono na poniższych rysunkach. 


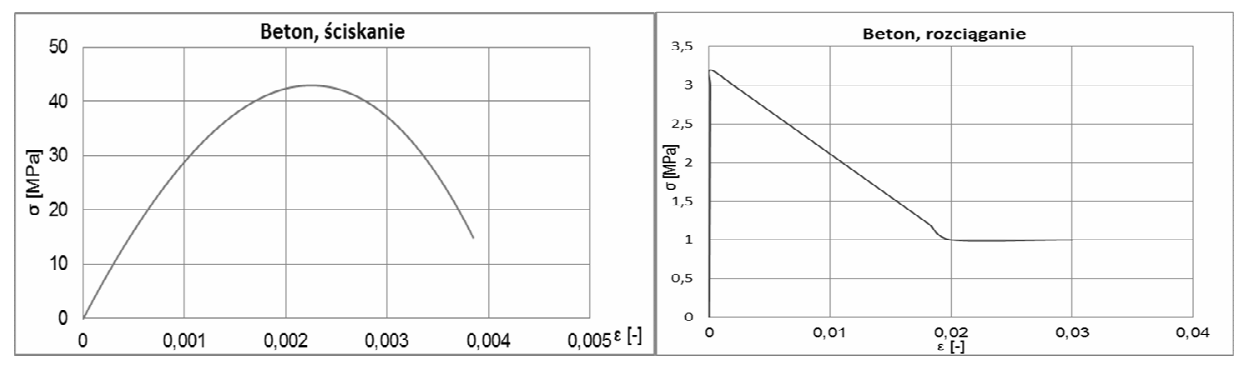

Rys. 3. Prawo fizyczne dla betonu, ściskanie, rozciąganie, na podstawie [4],[9]

Fig. 3. Physical law for concret, compression, tension, based on [4],[9]

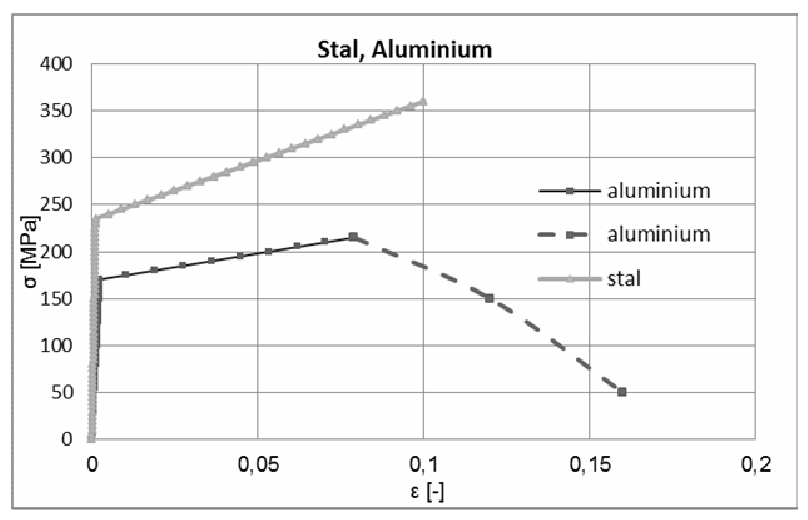

Rys. 4. Prawo fizyczne dla stali i aluminium

Fig. 4. Physical law for steel and aluminium

Obliczenia przeprowadzono stosując procedurę Abaqus-Standard z zastosowaniem metody przyrostowej Newtona-Raphsona. Obciążenie przykładane było w postaci zadanego w punktach wymuszenia kinematycznego jak dla standardowego schematu belki zginanej czteropunktowo. Obciążenie graniczne dla tego przypadku zaobserwowano w momencie pojawienia się opadającej gałęzi wykresu na ścieżce równowagi statycznej.

Modelując kontakt pomiędzy blachą stalową, a półką górną aluminiowego dwuteownika uwzględniono tarcie (różne współczynniki) i oceniono jego wpływ na nośność belki zespolonej aluminiowo-betonowej. Krzywą energii odkształcenia pokazano na rys. 5. Na rysunku 6 pokazano wykres zmian siły wymuszającej $\mathrm{w}$ jednym $\mathrm{z}$ punktów przyłożenia wymuszenia (przemieszczenia). 


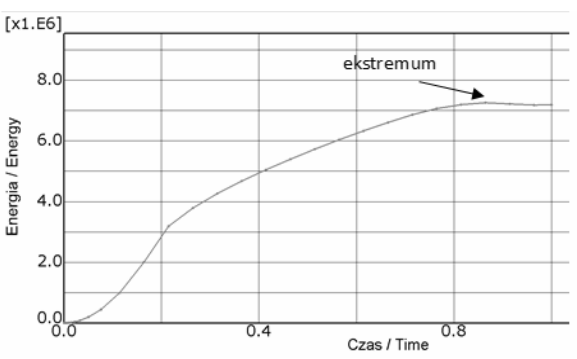

Rys. 5. Energia odkształcenia

Fig. 5. Strain energy

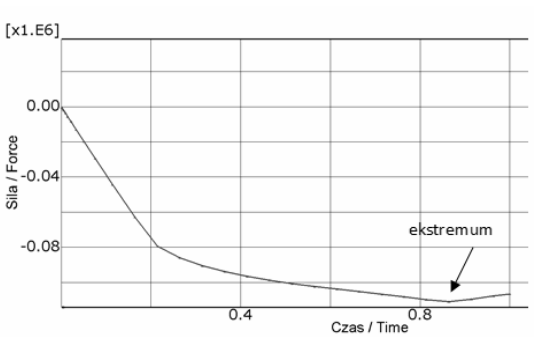

Rys. 6. Siła wymuszająca w jednym z punktów

Fig. 6. Force in one of the points

Na rys. 7 przedstawiono mapę naprężeń ekwiwalentnych Hubera-MisesaHencky'ego, a na rys. 8 mapę naprężeń głównych S33 w kroku, gdy pojawia się „opadanie" na ścieżce równowagi statycznej dla współczynnika tarcia wynoszącego 0,0 . Na rys. 7 widać, że belka aluminiowa uległa uplastycznieniu w środku rozpiętości, a rys. 8 , że w środku rozpiętości belki zespolonej została przekroczona wytrzymałość betonu na ściskanie.

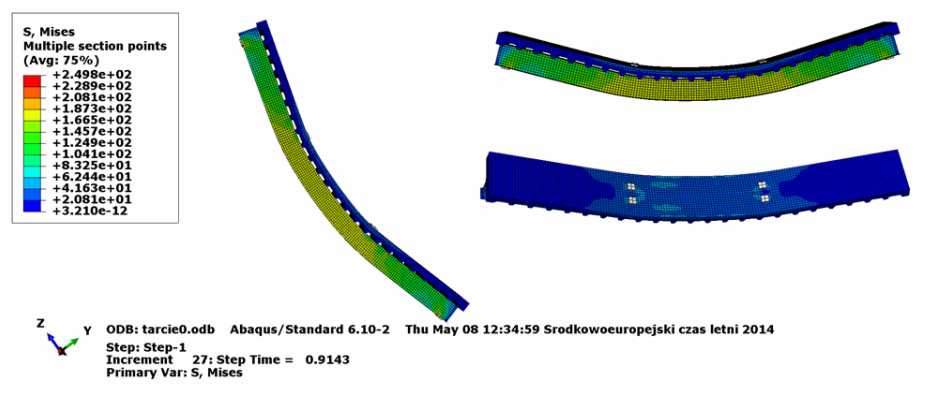

Rys. 7. Mapa naprężeń ekwiwalentnych Hubera-Misesa-Hencky'ego

Fig. 7. Map of stress equivalent Huber-Mises-Hencky

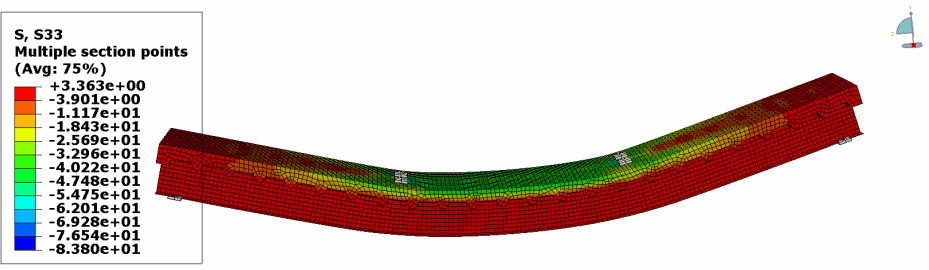

Rys. 8. Mapa naprężeń głównych S33

Fig. 8. Main stress S33 
Przemieszczenie belki aluminiowej w stosunku do płyty betonowej analizowano na podstawie dwóch punktów umieszczonych na krawędzi belki zespolonej, na styku belki aluminiowej z płytą betonowa. Jeden z punktów związany był z belką aluminiową, a drugi z płytą betonową. Przed analizą punkty te się pokrywały, a po przeprowadzeniu obliczeń numerycznych określono różnicę w ich położeniu mierzoną po kierunku podłużnym. Przemieszczenie belki w stosunku do płyty betonowej dla współczynnika tarcia wynoszącego 0,0 przedstawiono na rys. 9.

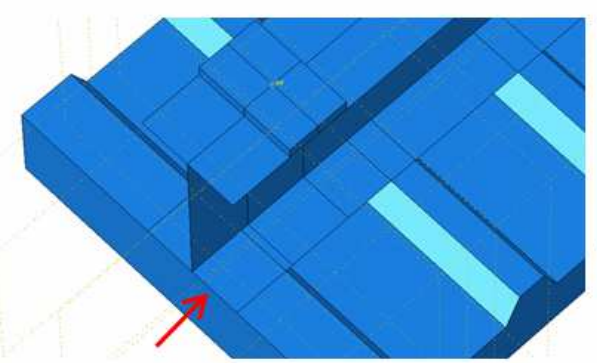

Brak przemieszczenia przed analizą

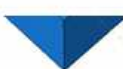

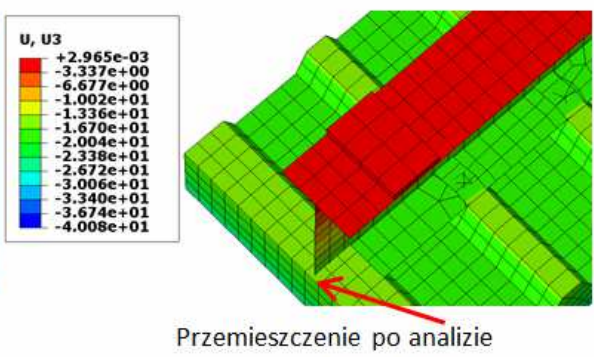

Przemieszczenie po analizie

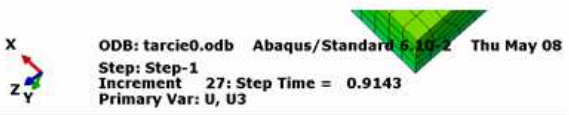

Rys. 9. Przemieszczenie belki aluminiowej w stosunku do płyty

Fig. 9. The displacement of the aluminium beam relative to the concrete plate

Wpływ tarcia na przemieszczenie belki aluminiowej w stosunku do płyty betonowej pokazano w tabeli 2 .

Tabela 2. Przemieszczenie belki aluminiowej w stosunku do płyty betonowej

Table 2. The displacement of the aluminium beam relative to the concrete plate

\begin{tabular}{|c|c|}
\hline Współczynnik tarcia & $\begin{array}{c}\text { Przemieszczenie belki } \\
\text { w stosunku do płyty }\end{array}$ \\
\hline 0,0 & $1,35 \mathrm{~mm}$ \\
\hline 0,1 & $1,26 \mathrm{~mm}$ \\
\hline 0,2 & $1,18 \mathrm{~mm}$ \\
\hline 0,3 & $1,10 \mathrm{~mm}$ \\
\hline 0,4 & $1,02 \mathrm{~mm}$ \\
\hline 0,5 & $1,05 \mathrm{~mm}$ \\
\hline
\end{tabular}

W momencie pojawienie się opadania gałęzi wykresu na ścieżce równowagi statycznej określono wartość maksymalnej siły wymuszającej, reakcję na podporze i obliczono moment w środku rozpiętość, który przyjęto jako nośność na zginanie belki aluminiowej. Wpływ tarcia na nośność belki zespolonej aluminiowo-betonowej pokazano w tabeli 3 . 
Tabela 3. Nośność na zginanie belki aluminiowo-betonowej

Table 3. Load bearing capacity of aluminium and concrete beam

\begin{tabular}{|c|c|}
\hline Współczynnik tarcia & Nośność na zginanie \\
\hline 0,0 & $375,129 \mathrm{kNm}$ \\
\hline 0,1 & $375,572 \mathrm{kNm}$ \\
\hline 0,2 & $375,883 \mathrm{kNm}$ \\
\hline 0,3 & $376,028 \mathrm{kNm}$ \\
\hline 0,4 & $376,123 \mathrm{kNm}$ \\
\hline 0,5 & $376,221 \mathrm{kNm}$ \\
\hline
\end{tabular}

\section{Podsumowanie}

Wpływ tarcia na nośność na zginanie jest pomijalnie mały. Stąd zasadne jest stosowanie przekładek zapobiegających korozji na styku aluminium - stal, nawet jeśli mają one zmniejszyć tarcie występujące między w/w materiałami. Planowane są badania laboratoryjne belki zespolonej aluminiowo-betonowej przedstawionej w artykule oraz badania podatności łączników.

\section{Literatura}

[1] Bromberek Z.: Energooszczędność a rozwój miast, Izolacje 1/2014, 2014.

[2] Błaszczyński T.: Budownictwo zrównoważone z elementami charakterystyki energetycznej, Dolnośląskie Wydawnictwo Edukacyjne, Wrocław 2013.

[3] Gwóźdź M.: Problemy projektowe współczesnych konstrukcji aluminiowych, Czasopismo Techniczne, Wydawnictwo Politechniki Krakowskiej, Kraków 2007.

[4] Kmiecik P., Kamiński M.: Modelling of reinforced concrete structures and composite structures with concrete strength degradation taken into cosideration, Archives of Civil and Mechanical Engineering, Vol. XI, No. 3, 2011.

[5] Kucharczuk W., Labocha S.: Konstrukcje zespolone stalowo-betonowe budynków, Arkady, Warszawa 2007.

[6] Mromliński R.: Konstrukcje aluminiowe, Arkady, Warszawa 1975.

[7] PN-EN 1994-1-1, Eurokod 4, Projektowanie zespolonych konstrukcji stalowobetonowych Część 1-1: Reguły ogólne i reguły dla budynków, Polski Komitet Normalizacyjny 2008

[8] PN-EN 1999-1-1, Eurokod 9, Projektowanie konstrukcji aluminiowych, Część 1-1: Reguły ogólne, Polski Komitet Normalizacyjny 2011

[9] PN-EN 1992-1-1, Eurokod 2, Projektowanie konstrukcji z betonu, Część 1-1: Reguły ogólne i reguły dla budynków, Polski Komitet Normalizacyjny 2008

[10] Polus Ł., Szumigała M., Analiza numeryczna nośności i sztywności belki zespolonej aluminiowo-betonowej, Jubileuszowa X Konferencja Naukowo Techniczna Konstrukcje Zespolone, Zielona Góra 2014

[11] Szumigała M., Polus Ł. Numeryczne modelowanie badania nośności łącznika do konstrukcji aluminiowo-betonowych, Aktualne problemy konstrukcji metalowych, II Międzynarodowa Polsko-Ukraińska Konferencja Naukowo-Techniczna, Fundacja Rozwoju Inżynierii Lądowej, Gdańsk 2014 


\section{PODZIĘKOWANIA}

Pracę wykonano w ramach działalności statutowej 01/11/DSPB/0305 oraz 01/11/DSMK/0292.

\section{INFLUENCE OF THE FRICTION ON THE CAPACITY OF THE ALUMINIUM AND CONCRETE BEAM}

\section{S u m m a r y}

In the article the influence of the friction between the aluminium beam and the steel sheet on the load bearing capacity is presented. The steel sheet is a formwork of the reinforcement plate. Aluminium and concrete structures are relatively young structure compared to composite steel and concrete structure. Aluminium structures have a lot of advantages. They are recyclable and resistant to corrosion. The composite aluminium and concrete structures are more durable than the composite steel and concrete structures. However, there is possible corrosion at the interface of aluminium and steel. Therefore, the aluminium beam should be isolate from the steel sheet using spacers. However, the use of spacers such as elastomeric reduces the effect of friction. The article evaluated influence of the friction on the bearing capacity of the beam and possibility to not include friction in the evaluation load bearing capacity of the composite beam. The model of composite aluminium and concrete beam was prepared. The model consisted of an aluminium I beam, a reinforcement plate, shear connectors and a steel sheet. From the numerical calculations obtained that the effect of friction on the bearing capacity of bending is negligible. Therefore, spacers may be used. Laboratory tests of composite aluminium and concrete beam and a test of shear connectors are planned.

Keywords: aluminium and concrete composite beam, numerical analysis

Przestano do redakcji: 06.12.2014 r.

Przyjęto do druku: 22.06.2015 r.

DOI:10.7862/rb.2015.67 